\title{
Budburst phenology and host use by Operophtera brumata (Linnaeus, 1758) (Lepidoptera: Geometridae) in three Mediterranean oak species
}

\author{
Yaussra Mannai $^{1,2}$ - Olfa Ezzine $e^{1,2}$ - Axel Hausmann ${ }^{3,4}$. Said Nouira ${ }^{2}$. \\ Mohamed Lahbib Ben Jamâa ${ }^{1}$
}

Received: 12 June 2016 / Accepted: 28 November 2016 / Published online: 6 February 2017

(C) INRA and Springer-Verlag France 2017

\begin{abstract}
- Key message Operophtera brumata L. performance varies among three Mediterranean oak species. Quercus canariensis Willd is more susceptible to infestation probably due to its (i) early leafing, (ii) high nutritional value for the larvae, and (iii) widespread abundance.

- Context Larvae of Operophtera brumata were observed for the first time in an outbreak in Tunisia affecting Quercus canariensis, Quercus afares Pomel, and Quercus suber L. Due to its polyphagous nature and the important ecological and economic damage it causes, it is most relevant to understand its interaction with North African oaks species.

- Aims In this paper, budburst phenology of the three oak species, larval performance, and genetic patterns of $O$. brumata were studied in northwestern Tunisia.

- Methods In the spring of 2010, 2011, and 2012, budburst phenology of host species and larval densities were monitored
\end{abstract}

Handling Editor: Aurelien SALLE

Contribution of co-authors Yaussra MANNAI: project design, field and laboratory data collection, data analysis, and paper writing Olfa EZZINE: project design, data analysis, and paper writing Axel HAUSMANN: data analysis and paper writing

Said NOUIRA and Mohamed Lahbib BEN JAMÂA: supervisors

Yaussra Mannai

farfallaflora@yahoo.fr

Olfa Ezzine

olfa.ezzine@gmail.com

Axel Hausmann

Axel.Hausmann@zsm.mwn.de

Said Nouira

saidnouira.ecologie@gmail.com weekly. Larval performance of $O$. brumata on the three oak species was analyzed. DNA extraction, PCR, and DNA sequencing were performed.

- Results Budburst of Q. canariensis and Q. afares was earlier than $Q$. suber. $Q$. canariensis was the most infested host. Larvae which fed on $Q$. canariensis had faster development, lower mortality, and higher pupal weight than larvae fed on $Q$. afares and $Q$. suber. Molecular analyses showed that Tunisian haplotypes were not different from those in Spain, Italy, and Germany.

- Conclusion Results indicated differences in larval performance. $Q$. canariensis was the most favorable host species. Its high density in the field and early leafing coinciding with larval hatching made this species particularly susceptible.

Keywords Q. canariensis $\cdot Q$. afares $\cdot Q$. suber $\cdot$ Winter moth $\cdot$ Tunisia

\section{Introduction}

Budburst timing varies among and within tree species (Van Dongen et al., 1997). Advances or delays in leafing are

Mohamed Lahbib Ben Jamâa benjamaaml@gmail.com

1 Laboratoire de Gestion et de Valorisation des Ressources Forestières, National Institute for Research in Rural Engineering Water and Forest (INRGREF), Bp 10, 2080 Ariana, Tunisia

2 Faculté des Sciences de Tunis, Campus Universitaire, El Manar, 1002 Tunis, Tunisia

3 Bavarian State Collection of Zoology (ZSM), Munich, Germany

4 Staatliche Naturwissenschaftliche Sammlungen Bayerns (SNSB), Munich, Germany 
important for insect life cycles (Foster et al. 2013). The close coincidence of budburst and larval hatch of spring-feeding generalist moth species was reported in many studies (Hunter 1992; Tikkanen and Julkunen-Tiitto 2003; Van Asch et al. 2010; Foster et al. 2013). Such synchronization is important for the survival and growth rate of the larvae, and therefore also, the expected fitness of the insects. For instance, in order to gain maximal weight, the larvae of the winter moth, Operophtera brumata L., an important forest defoliator (Van Dongen et al. 1997), need to enter a bud at budburst to feed upon the young leaves (Van Dongen et al. 1997). The dispersal behavior of $O$. brumata larvae might change with the onset of budburst (Hunter 1990). The newly hatched larvae often do not find suitable foliage on their natal tree and are forced to disperse. They can do this by "ballooning" (Holliday 1977; Hausmann and Viidalepp 2012).

O. brumata is a Holarctic species (Winstad et al. 2011; Hausmann and Viidalepp, 2012) widely distributed in Europe which has rapidly expanded its range colonizing other continents. It was recently reported as new for North Africa (Hausmann and Viidalepp 2012) and Tunisia (Mannai et al. 2015). Such extension of the distribution area offers the opportunity for the winter moth to contact and use new host plant species. In Tunisia, the main host species is $Q$. canariensis Willd but Quercus afares Pomel and Quercus suber L. are also attacked (Mannai et al. 2015). O. brumata is univoltine (Van Dongen et al. 1997), but the time for egg and larval developments, the length of pupation period and adult emergence varies throughout its range: in southern Italy, the egg stage lasts about 2 months and pupation for 8 months (Horgan 1993), whereas, in northern Europe, the egg stage lasts about 8 months and pupation lasts for about 3 months (Horgan 1993). Depending on the weather, the larva needs 12 months from hatching to maturity passing through five instars (Kúti et al. 2011). Adults emerge in the autumn or mid-winter, usually late October to early December in Central Europe, but this shifts to a late winter phenology (December to March) in southernmost Europe and North Africa (Hausmann and Viidalepp 2012).

Early field observations of $O$. brumata in Tunisia suggested restricted patterns of host use with feeding activity concentrated on only three host plants of the genus Quercus: $Q$. canariensis mixed with $Q$. suber and $Q$. afares in the Ain Zena reserve (Mannai et al. 2015). The use of novel hosts leads us to hypothesize firstly that some host adaptation or specialization might occur at regional/species level. Secondly, budburst phenology may play an important role which affects the interaction between this polyphagous insect and the host plant used by larvae. Field data and laboratory experiments were combined in order to investigate whether O. brumata showed differences in (i) density of larvae among years and host plants, (ii) feeding behavior during budburst and larval performance, measured by larval development time, larval mortality, and pupal weight on the three host species. In addition, the DNA barcode fragment of the COI gene was sequenced for O. brumata collected from these three Quercus species and compared with DNA barcodes from another Tunisian population (Mzara forest), from various European populations (Spain, Italy, and Germany) and from individuals of Operophtera fagata Scharfenbe as outgroup to test the association between genetic patterns and host use as well as test the hypothesis of a recent colonization of $O$. brumata in North Africa.

\section{Materials and methods}

\subsection{Study area}

The study site is located in the Ain Zena forest in northwestern Tunisia (alt. $950 \mathrm{~m}, 36^{\circ} 43^{\prime} \mathrm{N}, 8^{\circ} 51^{\prime} \mathrm{E}$ ) at the southern edge of a large forest in Ain Draham. Vegetation is dominated by $Q$. canariensis, $Q$. afares, and $Q$. suber (Mhamdi et al. 2013). $Q$. afares is an endemic North African species originating from hybridization between $Q$. suber and Q. canariensis (Mir et al. 2006). The average height of the three species at the study area is 7.3,12, and $18 \mathrm{~m}$ for $Q$. suber, $Q$. afares, and $Q$. canariensis, respectively.

\subsection{Tree density}

The density of $Q$. canariensis, $Q$. suber, and $Q$. afares was estimated by counting the number of trees in five $400 \mathrm{~m}^{2}$ plots, totaling an area of 0.2 ha.

\subsection{Budburst phenology and larvae density}

In 2010, 2011, and 2012, samples were taken on a weekly basis from mid-March to late April, for 6 weeks (W1-W6) to collect larvae and 9 weeks for budburst, until the first of May (W1-W9). Every week, two branches from 10 mature trees per host species were monitored, one low-level branch ( 2.5 to $5 \mathrm{~m}$ ) and one from crown height level $(>5 \mathrm{~m}$ ). Branches were carefully cut using a pole pruner and bagged in a large plastic bag to avoid losing larvae. In the laboratory, branches were used to count larvae density and the proportion of swollen buds (phenological stage in which $O$. brumata can colonize buds (Hunter 1990)).

\subsection{Laboratory feeding trials}

The performance of $O$. brumata on $Q$. canariensis, Q. afares, and $Q$. suber was compared in laboratory feeding trials. 
Experiments were performed in the spring of 2011, coinciding with the budburst of the host plants. Neonate larvae were obtained from branches collected in the field in March 2011 and were individually placed in Petri dishes, kept at $25 \pm 2{ }^{\circ} \mathrm{C}$ and a light regime of 12:12 L:D (light:dark) as in natural conditions and reared ad libitum on leaves of each tested oak species. Thirty larvae, repeated 3 times, were used for each tested plant. Young still-expanding leaves were collected daily from plantlets of each species, planted in the same conditions at the nursery of the INRGREF. Larvae were checked daily and numbers of molted larvae were recorded. Larval development time for each tested oak species was reported. To evaluate larval performance, development time, larvae survival, and pupal weight of the 5th instar larvae were assessed on each tested species as biological parameters.

\subsection{Mortality and pupal weight of field collected larvae}

First, second, and third instar larvae were collected only from $Q$. canariensis and $Q$. afares as they were absent on $Q$. suber. Fourth and fifth instar larvae were collected from $Q$. canariensis, Q. afares, and Q. suber. Each larva was kept individually in a Petri dish and reared to pupation on young expanding leaves of each host species collected daily from plantlets at the INRGREF nursery. The Petri dishes were examined daily to record the number of molting and dead larvae. Rearing tests were done in the spring of 2011. Pupal weight of the 5th instar larvae collected from the field and larvae developed in the laboratory (from the second instar to pupation) on $Q$. canariensis, $Q$. afares, and $Q$. suber were compared in order to investigate the suitability of these hosts for winter moth larvae.

\subsection{Molecular analysis}

Mature larvae were collected by hand from the host plants (Q. canariensis, Q. afares, and Q. suber) in April 2011 from Ain Zena and Mzara. To prevent the sampling of siblings, each larva was collected from a different tree. Pupae were collected from the soil next to infested trees. Larvae and pupae were preserved in $96 \%$ ethanol. One or two segments of larval thorax and the cremaster part of pupae were sampled into lysis plates for DNA barcoding. In total, 15 individuals were sampled. DNA extraction, PCR, and DNA sequencing were performed at the Canadian Centre for DNA Barcoding, Guelph, Canada (CCDB), following standard high-throughput protocol, that can be accessed under http://ccdb.ca/resources.php. PCR amplification with a single pair of primers (Ivanova et al. 2006 ) consistently recovered a 658-bp region near the $5^{\prime}$ terminus of the mitochondrial cytochrome $\mathrm{c}$ oxidase 1 (CO1) gene that included the standard $648 \mathrm{bp}$ barcode region for the animal kingdom (Hebert et al. 2003). PCR primers used were LepF1/LepR1 (Hebert et al. 2003). Quality check of the sequence data followed the CCDB standards and included the accurate examination of trace files as well as exclusion of chimaera and sequences with stop codons. DNA extracts are stored at the CCDB, with aliquots being deposited in the DNA Bank facility of the ZSM (see http://www.zsm.mwn.de/dnabank/). Sequences and metadata are hosted in BOLD (Barcode of Life Data Systems, project INRGR “Global Geometridae/Lepidoptera of Tunisiacork oak defoliators-INRGREF") and are accessible and downloadable in the public dataset DS-OPEROPH. All sequences are deposited also in GenBank according to the $\mathrm{BOOL}$ data release policy. Sequence ID numbers on BOLD are provided in Table 1. Images, GPS coordinates, and sequence trace files for each specimen as well as details on host institution can be obtained from the Barcode of Life Data System (BOLD; Ratnasingham and Hebert 2007), public DS-OPEROPH.

Eight sequences of German specimens of $O$. brumata (A. Hausmann), one of a southern Italian specimen (M. Infusino) and one sequence of a southern Spanish specimen (A. Hausmann) were included into the analysis. German and Italian sequences of 8 individuals of $O$. fagata were used as outgroup. A first analysis was performed with the tools of BOLD database and was then refined on MEGA6 and MEGA 7 (Tamura et al., 2013; Kumar et al. 2016) constructing a Maximum Likelihood (ML) Tree including 21 Operophtera specimens from the western Palearctic (3 from Tunisia), bootstrap method, 500 replicates, Tamura-Nei model, complete deletion, bootstrap values indicated when $>50 \%$. Alignment was based on the alignment tools of BOLD database. Manual alignment check revealed no errors (Fig. 4).

\subsection{Statistical analysis}

The statistical analysis was performed using the SPSS-10.0 software package for Windows.

Generalized linear models (GLMs) were applied to the following dependent variables: (1) the Julian day when $50 \%$ of budburst occurred; (2) the number of larvae per branch, considering tree species and year as factors; (3) larvae development (number of days spent in each instar), considering tree species as a factor. A Normal distribution model best fitted the Julian day when $50 \%$ of budburst occurred and larvae development. A Poisson distribution model best fitted the number of larvae per branch. The effect of each tested oak species on the larval development time and the pupal weight was assessed with an analysis of variance (ANOVA) and complemented by multiple comparisons of means by the SNK test (Student-Newman-Keuls) and was expressed as mean \pm standard error of mean (MSE).

The proportion of dead larvae among the total individuals obtained in the feeding experiments was analyzed by GLM using a Binomial model with log link function, considering the factor plant species. Results are presented in the form of the Wald's chi-square test value $\left(\chi^{2}\right)$, parameter estimates and the respective $P$ value. 
Table 1 Insects used for molecular analyses: 21 specimens of Operophtera brumata and O. fagata. BOLD sequence IDnumbers, sites, and host plant

\begin{tabular}{|c|c|c|c|c|}
\hline Species & Stage & $\begin{array}{l}\text { Sequence-ID number } \\
\text { in BOLD }\end{array}$ & Location & Host plant \\
\hline \multirow[t]{13}{*}{ Operophtera brumata } & \multirow[t]{3}{*}{ Pupa } & GWOSP600-11 & Ain zena (Tunisia) & Q. afares \\
\hline & & GWOSP595-11 & Mzara (Tunisia) & Q. canariensis \\
\hline & & GWOSP587-11 & Ain zena (Tunisia) & Q. canariensis \\
\hline & \multirow[t]{6}{*}{ Adult } & GBLAC679-13 & Bavaria, Oberbayern (Germany) & - \\
\hline & & GBLAC990-13 & Bavaria, Oberbayern (Germany) & - \\
\hline & & GBLAC166-13 & Bavaria, Oberbayern (Germany) & - \\
\hline & & GWOSP887-11 & Sicily (Italy) & - \\
\hline & & GWOTD346-12 & Andalusia (Spain) & - \\
\hline & & GBLAA454-14 & Schleswig-Holstein (Germany) & - \\
\hline & \multirow[t]{4}{*}{ Larva } & GWORB1495-08 & Bavaria, lower Bavaria (Germany) & Q. robur \\
\hline & & GWORO977-09 & Lower Saxony (Germany) & - \\
\hline & & GWORO967-09 & Lower Saxony (Germany) & - \\
\hline & & GWORO954-09 & Lower Saxony (Germany) & - \\
\hline \multirow[t]{8}{*}{ Operophtera fagata } & \multirow[t]{7}{*}{ Adult } & GBLAC168-13 & Saarland (Germany) & - \\
\hline & & GBLAC993-13 & Saxony (Germany) & - \\
\hline & & GBLAF596-14 & Brandenburg, Barnim (Germany) & - \\
\hline & & GWOTD330-12 & Calabria (Italy) & - \\
\hline & & GWOTD332-12 & Calabria (Italy) & - \\
\hline & & GWORB791-07 & Bavaria, south (Germany) & - \\
\hline & & GBLAC167-13 & Saarland (Germany) & - \\
\hline & Larva & GWORO972-09 & Lower Saxony (Germany) & - \\
\hline
\end{tabular}

(-) Absence of information about host plant in database

\section{Results}

\subsection{Tree density and budburst variation}

Q. canariensis was the most abundant species in the studied region with an average density of 700 trees/ha followed by $Q$. suber and $Q$. afares with an average density of 175 trees/ha and 60 trees/ha, respectively. The Julian day when $50 \%$ of budburst occurred varied between host plants $\left(\chi_{2}^{2}=13.03, p<0.001\right)$ and years $\left(\chi_{2}^{2}=13.78\right.$, $p<0.001)$. The interaction term was also significant $\left(\chi_{4}^{2}=18.89, p<0.001\right)$. Budburst of $Q$. afares and Q. canariensis began in late March, but budburst of Q. suber occurred about 3 weeks later (Fig. 1). In 2010 and $2011,50 \%$ of $Q$. canariensis budburst occurred 1 week before $Q$. afares. In 2012, budburst of $Q$. canariensis began a week after $Q$. afares. For all years, $Q$. suber budburst was 3 to 4 weeks later (Fig. 1).
Fig. 1 Evolution of budburst of $Q$. canariensis, $Q$. afares and Q. suber in 2010, 2011, and 2012

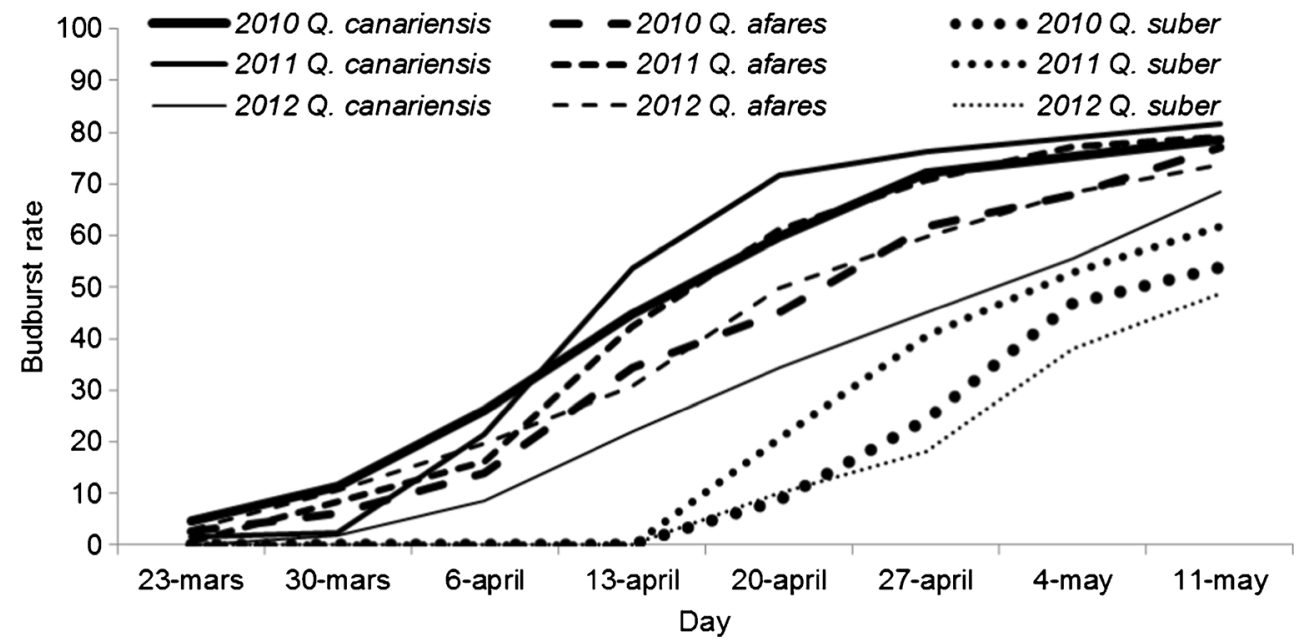




\subsection{Larval density on host plants}

For 6 weeks, a total of 1057, 1011, and 355 larvae were collected in 2010, 2011, and 2012, respectively. The average number of larvae per branch varied between host species $\left(\chi_{2}^{2}=883.12, p<0.001\right)$ and years $\left(\chi_{2}^{2}=115.50\right.$, $p<0.001)$; the interaction term was also significant $\left(\chi_{4}^{2}=112.50, p<0.001\right)$. For all weeks, mean larval numbers were higher on $Q$. canariensis than on $Q$. afares and $Q$. suber (Table 2). For all host species, larval density was highest in April (Table 2).

\subsection{Larval development and mortality}

In the laboratory experiment, total larval development time from the $1 \mathrm{st}$ instar to the 5 th was shorter on $Q$. canariensis (36.5 \pm 0.3 days) than on $Q$. afares $(40 \pm 0.3$ days) and $Q$. suber (46.2 \pm 0.3 days). The host species had a significant effect on larval development $\left(F_{(2,206)}=245.84, p<0.001\right)$. For each instar larva, the development was faster on Q. canariensis than on $Q$. afares and $Q$. suber (Fig. 2).

Death cause was in most cases unknown. Mortality was higher on $Q$. afares for the 1 st and 2 nd instar larvae and greater on $Q$. suber for the 4 th and 5 th instar larvae (Fig. 3). The host species had a significant effect on the proportion of $3 \mathrm{rd}$ $\left(\chi_{1}^{2}=11.34, p<0.001\right)$ and 4 th $\left(\chi_{2}^{2}=7.3, p<0.05\right)$ instar dead larvae.

\subsection{Pupal weight}

The pupal weight varied significantly among species, in the laboratory trials $\left(F_{(2,50)}=38.12, p<0.001\right)$ and in the field $\left(F_{(2,73)}=13.96, p<0.001\right)$. It was higher for $Q$. canariensis with an average of $27.2 \pm 0.5 \mathrm{mg}$ and $28.8 \pm 0.5 \mathrm{mg}$, from laboratory feeding trials and the field, respectively, than $Q$. afares at $24.4 \pm 0.6 \mathrm{mg}$ and $26.5 \pm 0.5 \mathrm{mg}$ and $Q$. suber at $20.4 \pm 0.6 \mathrm{mg}$ and $23.8 \pm 0.9 \mathrm{mg}$.

\subsection{Molecular data and patterns}

A total of 15 barcode sequences of Tunisian $O$. brumata were sequenced to the full barcode region of $658 \mathrm{bp}$ (BOLD, project INRGR http://www.barcodinglife.com/Global Geometridae/Lepidoptera of Tunisia-cork) represented in Fig. 4. No genetic differences were found between the specimens feeding on the various host plants. All 15 Tunisian DNA barcodes belong to exactly the same haplotype and perfectly match the haplotype of the populations examined from a Tunisian forest (Mzara) next to Ain Zena, as well as those from Spain, Italy, and Germany (see Fig. 4). On the BOLD database, there are additional data of the same haplotype from Morocco, France, the Netherlands, Austria, UK, and Canada. Populations with slightly diverging haplotypes (diverging by 1-2 basepairs only) have been barcoded from northern Germany, Finland, and UK The genetic distance from $O$. fagata, chosen as outgroup, was $7.0 \%$ (Fig. 4).

\section{Discussion}

The winter moth is a polyphagous insect that takes advantage of many different host species, when available; oak is usually the primary host with a high density and greater defoliation (O’Donnell 2015). Larval density was high in 2010 and 2011 on all the oak species considered, especially on Q. canariensis. Then in 2012, the density fell sharply (Table 2). In the field, $Q$. canariensis trees had a higher density on average than the other two oaks. It was the most infested host species. Cunningham et al. (2001) showed that when the abundance of one host species is high, the probability that the insect will land on this species is greater. Furthermore, phenological differences among and within host species are very important factors which affect host use and adaptations of $O$. brumata. Many works have shown that there is a large annual variation of budburst of oak (Wint 1983; Fraval 1984; Du Merle 1988; Van Dongen et al. 1997; Pinto

Table 2 Mean number of larvae on each host species per week and per year

\begin{tabular}{lllllllll}
\hline Year & Host plant & W1 & W2 & W3 & W4 & W5 & W6 & Mean number of larvae \\
\hline \multirow{2}{*}{2010} & Q. canariensis & $3.1 \pm 1.4$ & $7.5 \pm 2.7$ & $14.7 \pm 7.2$ & $23.2 \pm 7$ & $21.2 \pm 6.2$ & $15.5 \pm 3.6$ & $12 \pm 2$ \\
& Q. afares & $0.4 \pm 0.3$ & $3.5 \pm 1.3$ & $4.6 \pm 1.6$ & $2.7 \pm 0.8$ & $2.2 \pm 1$ & $1.9 \pm 0.6$ & $2.7 \pm 0.4$ \\
& Q. suber & 0 & 0 & 0 & $1.9 \pm 0.9$ & $1.9 \pm 0.8$ & $1.4 \pm 0.8$ & $1.7 \pm 0.6$ \\
2011 & Q. canariensis & $1.2 \pm 0.4$ & $9.4 \pm 2$ & $24.2 \pm 5.7$ & $20.8 \pm 6.3$ & $16.8 \pm 4.4$ & $4.9 \pm 2.1$ & $12.9 \pm 2$ \\
& Q. afares & 0 & $3.6 \pm 0.9$ & $5.9 \pm 1.2$ & $3.7 \pm 0.8$ & $3.1 \pm 1$ & $0.8 \pm 0.5$ & $2.8 \pm 0.4$ \\
& Q. suber & 0 & 0 & 0 & 0 & $2.5 \pm 1.4$ & $4.2 \pm 1.5$ & $1.13 \pm 0.3$ \\
& Q. canariensis & $3.5 \pm 1.2$ & $2.4 \pm 1$ & $6.3 \pm 2.6$ & $4 \pm 1.3$ & $2.3 \pm 1$ & $2.7 \pm 1$ & $3.5 \pm 0.6$ \\
& Q. afares & $1.7 \pm 0.6$ & $2.4 \pm 0.7$ & $3.8 \pm 1.3$ & $3.3 \pm 1.2$ & $1.1 \pm .5$ & $0.8 \pm 0.4$ & $2.2 \pm 0.4$ \\
& Q. suber & 0 & 0 & 0 & 0 & $0.8 \pm 0.5$ & $0.4 \pm 0.2$ & $0.2 \pm 0.1$ \\
\hline
\end{tabular}

W1 3rd week of March, W2 4th week of March, W3 1st week of April, W4 2nd week of April, W5 3rd week of April, W6 4th week of April 
Fig. 2 Development time of $O$. brumata in days $( \pm \mathrm{SE})$ from first (L1) to fifth (L5) larval instar

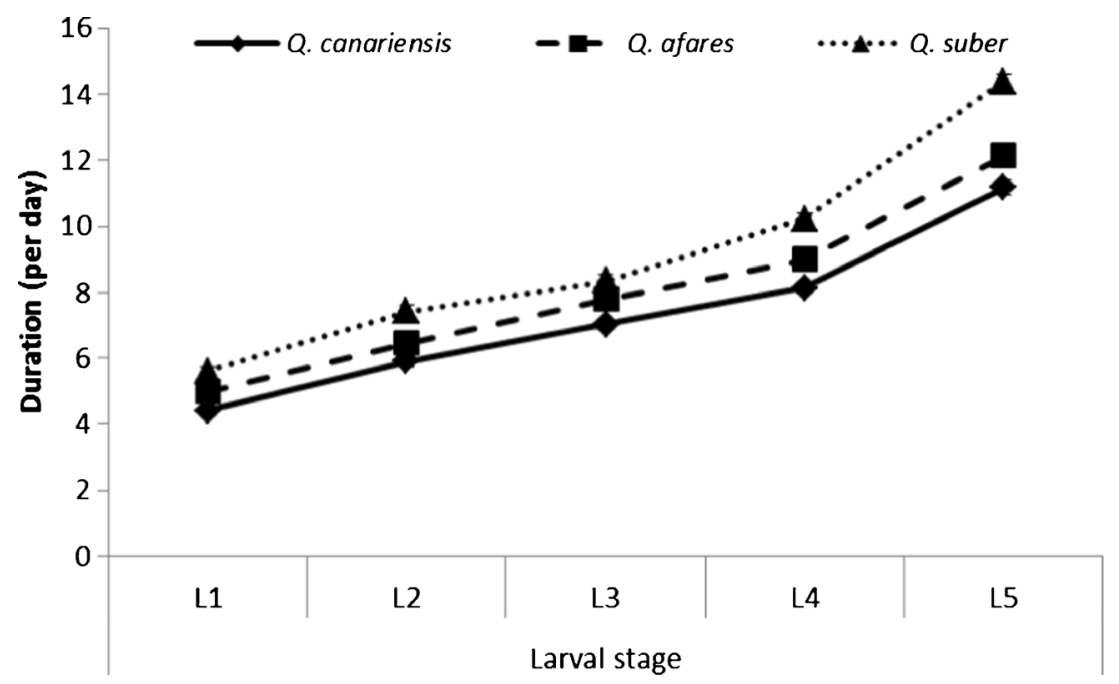

et al. 2011). Budburst timing did not differ between $Q$. canariensis and $Q$. afares whereas that of $Q$. suber occurred about 3 weeks later than the other two species (Fig. 1). In a given region with several host species, $O$. brumata will feed mainly on the host which budburst phenology coincides with its larval hatching. Once larvae emerged, they needed young leaves available on deciduous to semi-evergreen Quercus species: Q. canariensis and $Q$. afares. On the evergreen oak $Q$. suber, larvae found only old leaves, which explain the absence of young larvae on this species (Table 2). This suggests that the phenology of $Q$. canariensis allows a high colonization by $O$. brumata. $Q$. canariensis probably offers more chances for $O$. brumata to survive because of early leafing and intense budburst which exceeds $50 \%$ at the peak density of the insect (Fig. 1, Table 2). Hunter (1992) found that Quercus robur L. trees that leaf out early have the highest density of caterpillars.

The suitability of host species for larva development and survival of polyphagous insects differs from one host plant species to another. Generalist Lepidoptera species can vary greatly in their growth efficiency on different natural host plants (Feeny 1970). Many studies have focused on the effect

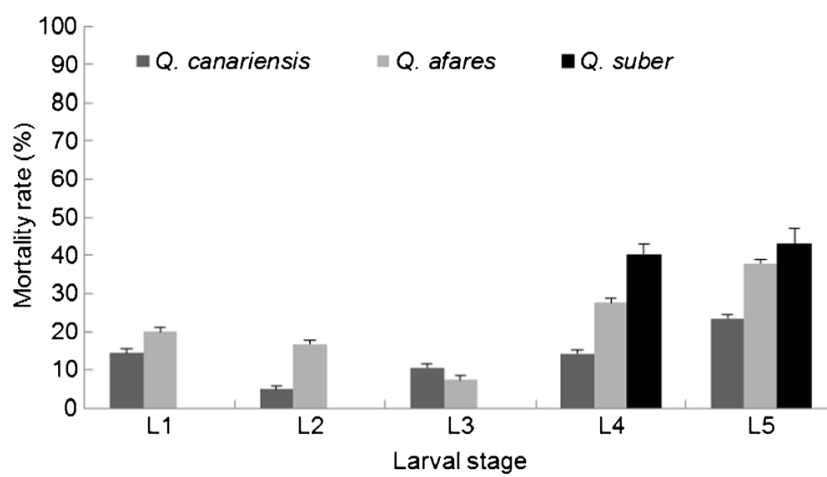

Fig. 3 Mortality rate $( \pm \mathrm{SE})$ of each larval stage (first (L1) to fifth (L5) larval instar) collected from the field of the host plant on larval performance (Hunter 1992; Tikkanen and Lyytikainen-Saarenmaa 2002). O. brumata performance varies among these three Mediterranean oak species which would offer different food quality. Budburst of $Q$. canariensis and $Q$. afares occurred at the same time. The shortest larval development time was recorded for larvae feeding on $Q$. canariensis which was the most infested host, while the longest development time was recorded for those feeding on Q. suber (Fig. 2). O'Donnell (2015) showed that larvae of O. brumata fed on Q. rubra L. and Malus domestica Borkh had faster development and lower mortality than larvae fed on Acer rubrum L., Betula papyrifera Marshall, Prunus pensylvanica L.f., Vaccinium angustifolium Aiton, and V. corymbosum L. Similarly, Ruuhola et al. (2001) also observed that larval growth of the winter moth on Salix phylicifolia L. was significantly faster than on Salix pentandra L. and on Salix myrsinifolia Salisb. Larval growth is clearly better on certain hosts than others, depending on host nutritional quality and resistance mechanisms (Kirsten and Topp 1991). The ability of generalist Lepidoptera to complete larval development, even at the cost of increased development times (Wint 1983), is the most important feature of their polyphagous habit (Warrington 1985). Results of the pupal weight of O. brumata suggest that food quality may have influenced pupal mass. Tikkanen (2000) demonstrated that pupal weight of $O$. brumata larvae reared on $Q$. robur varied between 16 and $42.2 \mathrm{mg}$. In the data obtained here, pupae of larvae reared on $Q$. canariensis were heavier than those reared on $Q$. afares and $Q$. suber.

According to the slow-growth-high-mortality hypothesis (Clancy and Price 1987), the extended feeding period makes insect larvae more susceptible to attacks by predators, parasitoids, and pathogens, resulting in a higher mortality in natural environments (Häggström and Larsson 1995). Host species also affects mortality of $O$. brumata larvae (Wint 1983). Mortality of 4 th and 5 th instar larvae was greater on 


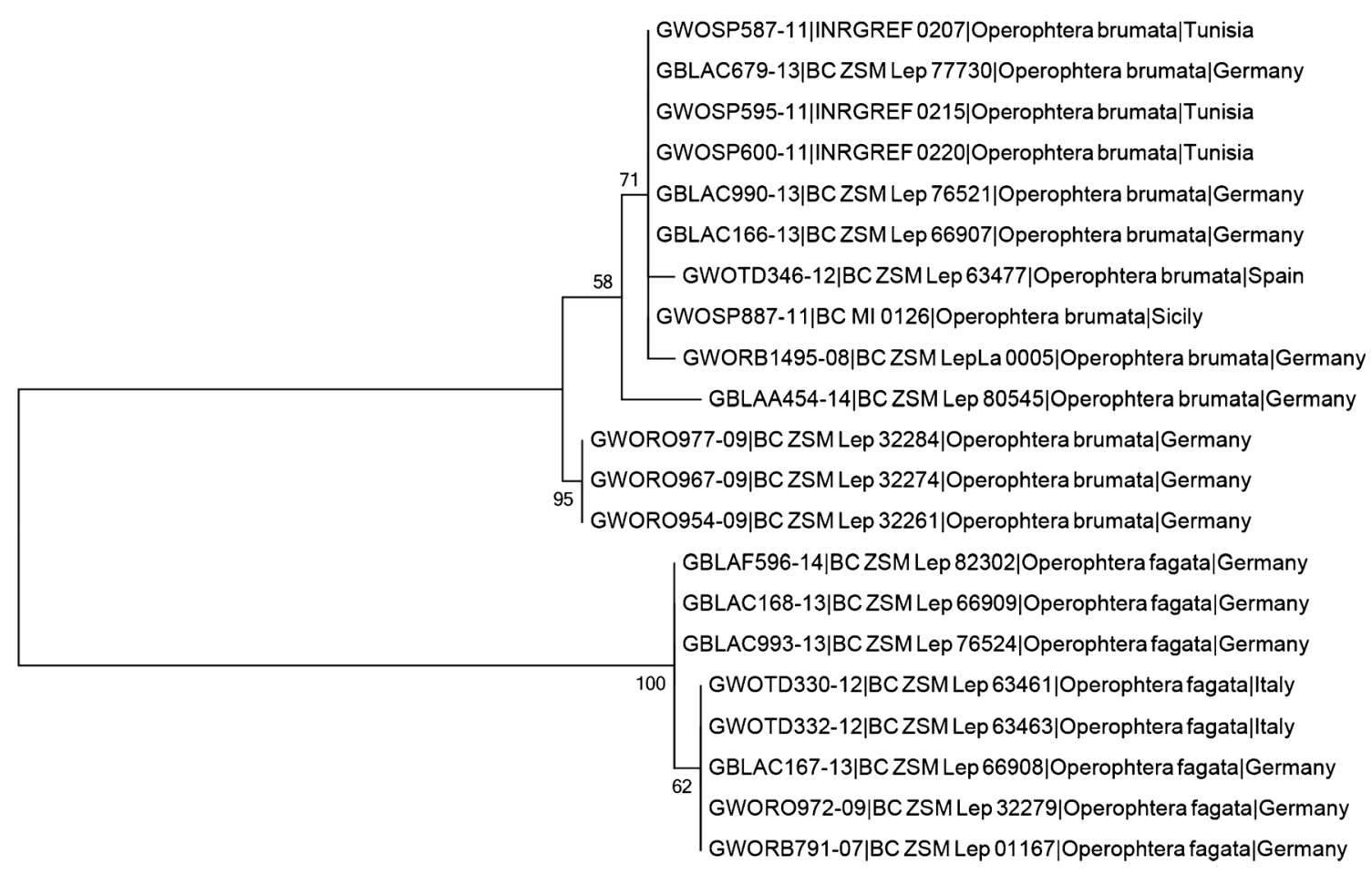

0.01

Fig. 4 Maximum Likelihood (ML) Tree including 21 Operophtera specimens from the western Palearctic ( 3 from Tunisia), constructed with MEGA6 and MEGA7 (Tamura et al. 2013; Kumar et al. 2016),

Q. suber than on $Q$. canariensis and $Q$. afares (Fig. 3). Caterpillars would then experience higher parasitism rates on $Q$. suber (which should be tested in further experiments).

Molecular data and patterns show no genetic difference between the Tunisian populations and the European "main pool" of that species belonging all to one and the same haplotype (Fig. 4). This result (1) agrees with the absence of host specialization (potentially leading to complex haplotype diversification) and the polyphagous life history of this species; and (2) clearly supports the hypothesis of a recent expansion of the distribution area instead of an overlooked occurrence of a long-term isolated population in North Africa. First instar larvae of $O$. brumata are abseiling on silky threads enabling to long-distance dispersal by wind (Hausmann and Viidalepp, 2012). Moreover, the species has been recorded in Morocco (Hausmann and Viidalepp 2012), supposedly colonized from Spain. The latter country, therefore, has to be regarded as a potential origin of the Tunisian populations as well as Italy. The hypothesis of a recent colonization due to an anthropogenous transport of immature stages over long distances with tree seedlings is not excluded, but is questioned by the fact that Tunisia has not seen any colonization from one of the many other Central European defoliating moth species (Hausmann and Viidalepp 2012). bootstrap method, 500 replicates, Tamura-Nei model, complete deletion, bootstrap values indicated when $>50 \%$

\section{Conclusion}

We concluded that the deciduous $Q$. canariensis was more susceptible to infestation by the winter moth than other species due to its high density in the field, early leafing, and best food quality offered to this insect. There are significant differences in the performance of larval development on the different hosts. These differences are reflected in the various components of individual fitness, such as larval development time, larval mortality, and pupal weight.

Population abundance of the winter moth observed after 2011 was not sufficient to damage trees. However, this insect was observed in other cork oak forests (Ain El Baya in 2013 and El Jouza in 2015), suggesting further expansion. Winter moth populations should be managed through constant monitoring for early detection of outbreaks.

Acknowledgments Thanks to Mabrouk GRAMI (CFAR, Tunisia) and forest technicians for their valuable help in the field. The genetic analyses have received considerable support from Paul D. N. HEBERT and the Biodiversity Institute of Ontario (BIO) and the Canadian Centre for DNA Barcoding (CCDB University of Guelph). The data management and analysis system BOLD was provided by Sujeevan RATNASINGHAM. We wish to thank Christie NIELSEN CHAAR and Emna DARGHOUTHI for their assistance with the language editing. 


\section{Compliance with ethical standards}

Funding Funding was provided to achieve the presented results and was given from the National Institute for Research in Rural Engineering, Water and Forest (INRGREF) and Genome Canada (Ontario Genomics Institute) in the framework of the $\mathrm{BBOL}$ program, WG 1.9.

\section{References}

Clancy KM, Price PW (1987) Rapid herbivore growth enhances enemy attack: sublethal plant defenses remain a paradox. Ecology 68:733737. doi:10.2307/1938479

Cunningham JP, West SA, Zalucki MP (2001) Host selection in phytophagous insects: a new explanation for learning in adults. Oikos 95: 537-543. doi:10.1034/j.1600-0706.2001.950319.x

Du Merle P (1988) Phenological resistance of oaks to the green leafroller, Tortrix viridiana (Lepidoptera: Tortricidae). In: Mattson WJ, Levieux J, Bernard-Dagan C (eds) Mechanisms of woody plant defenses against insects. Springer, Berlin Heidelberg New York, pp 215-226

Feeny P (1970) Seasonal changes in oak-leaf tannins and nutrients as a cause of spring feeding by winter moth caterpillars. Ecology 51: 565-581. doi:10.2307/1934037

Foster JR, Townsend PA, Mladenoff DJ (2013) Mapping asynchrony between gypsy moth egg-hatch and forest leaf-out: putting the phenological window hypothesis in a spatial context. For Ecol Manag 287:67-76. doi:10.1016/j.foreco.2012.09.006

Fraval A (1984) Influence de la qualité et de la quantité de l'alimentation sur les fluctuations des populations de Lymantria dispar L. (Lep. Lymantriidae) en forêt de la Mamora (Maroc). Agronomie 4:819828. doi:10.1051/agro:19840903

Häggström H, Larsson S (1995) Slow larval growth on a suboptimal willow results in high predation mortality in the leaf beetle Galerucella lineola. Oecologia 104:308-315. doi:10.1007 /BF00328366

Hausmann A, Viidalepp J (2012) The geometrid moths of Europe, vol 3. Apollo Books, Vester Skerninge

Hebert PDN, Ratnasingham S, De Waard JR (2003) Barcoding animal life: cytochrome c oxidase subunit 1 di-vergences among closely related species. Proc R Soc Lond B Biol Sci 270:S96-S99. doi:10.1098/rsbl.2003.0025

Holliday NJ (1977) Population ecology of winter moth (Operophtera brumata) on apple in relation to larval dispersal and time of budburst. J Appl Ecol 14:803-813. doi:10.2307/2402812

Horgan FG (1993) Factors affecting the mortality of winter moth in the lower mainland of British Columbia. Dissertation, University of British Columbia, Vancouver

Hunter MD (1990) Differential susceptibility to variable plant phenology and its role in competition between two insect herbivores on oak. Ecol Entomol 15:401-408. doi:10.1111/j.1365-2311.1990.tb00823.x

Hunter MD (1992) A variable insect-plant interaction: the relationship between tree budburst phenology and population levels of insect herbivores among trees. Ecol Entomol 16:91-95. doi:10.1111 /j.1365-2311.1992.tb01046.x

Ivanova V, Dewaard JR, Hebert PDN (2006) An inexpensive, automation friendly protocol for recovering high quality DNA. Mol Ecol Notes:6:998-61002. doi:10.1111/j.1471x8286.2006.01428.x

Kirsten K, Topp W (1991) Acceptance of willow-species for the development of the winter moth, Operophtera brumata (Lep., Geometridae). J Appl Entomol 111:457-468. doi:10.1111/j.14390418.1991.tb00348.x
Kumar S, Stecher G, Tamura K (2016) MEGA7: molecular evolutionary genetics analysis version 7.0 for bigger datasets. Mol Biol Evol 33: 1870-1874. doi:10.1093/molbev/msw074

Kúti ZS, Hirka A, Hufnagel L, Ladanyl M (2011) A population dynamical model of Operophtera brumata L. extended by climatic factors. Appl Ecol Env Res 9:433-447. doi:10.15666/aeer/0904_433447

Mannai Y, Ezzine O, Nouira S, Ben Jamâa ML (2015) First report of the winter moth Operophtera brumata on Quercus canariensis and Q. afares in north west of Tunisia. TJPP 10:69-74

Mhamdi S, Brendel O, Montpied P, Ghouil-Amimi H, Hasnaoui I, Dreyer E (2013) Leaf morphology displays no detectable spatial organization in the relict Quercus afares Pomel compared to the co-occurring parental species $Q$. canariensis Willd and $Q$. suber L. Ann For Sci 70:675-684. doi:10.1007/s13595-013-0312-x

Mir C, Toumi L, Jarne P, Sarda V, Di Giusto F, Lumaret R (2006) Endemic North African Quercus afares Pomel originates from hybridisation between two genetically very distant oak species $(Q$. suber $\mathrm{L}$. and $Q$. canariensis Willd.): evidence from nuclear and cytoplasmic markers. Heredity 96:175-184. doi:10.1038/sj.hdy.6800782

O'Donnell K M (2015) The relationship between the winter moth (Operophtera brumata) and its host plants in Coastal Maine. Electronic Theses and Dissertations. University of Maine

Pinto CA, Henriques MO, Figueiredo JP, David JS, Abreu FG, Pereira JS, Correia I, David TS (2011) Phenology and growth dynamics in Mediterranean evergreen oaks: effects of environmental conditions and water relations. For Ecol Manag 262:500-508. doi:10.1016/j. foreco.2011.04.018

Ratnasingham S, Hebert PDN (2007) BOLD: the barcode of life data system. Mol Ecol Notes 7:355-364. doi:10.1111/j.14718286.2007.01678.x

Ruuhola T, Tikkanen OP, Tahvanainen J (2001) Differences in host use efficiency of larvae of a generalist moth, Operophtera brumata of three chemically divergent Salix species. J Chem Ecol 27:15951615. doi:10.1023/A:1010458208335

Tamura K, Stecher G, Peterson D, Filipski A, Kumar S (2013) MEGA6: molecular evolutionary genetics analysis version 6.0. Mol Biol Evol 30:2725-2729. doi:10.1093/molbev/mst197

Tikkanen OP (2000) Adaptation of a generalist moth, Operophtera brumata, to host plants. Dissertation, University of Joensuu

Tikkanen OP, Julkunen-Tiitto R (2003) Phenological variation as protection against defoliating insect: the case of Quercus robur and Operophtera brumata. Oecologia 139:244-251. doi:10.1007 /s00442-003-1267-7

Tikkanen OP, Lyytikainen-Saarenmaa P (2002) Adaptation of a generalist moth, Operophtera brumata, to variable budburst phenology of host plants. Entomol Exp Appl 103:123-133. doi:10.1046/j.15707458.2002.00966.x

Van Asch M, Julkunen-Tiito R, Visser ME (2010) Maternal effects in an insect herbivore as a mechanism to adapt to host plant phenology. Funct Ecol 24:1103-1109. doi:10.1111/j.1365-2435.2010.01734.x

Van Dongen S, Backeljau T, Matthysen E, Dhondt AA (1997) Synchronization of hatching date with budburst of individual host trees (Quercus robur) in the winter moth (Operophtera brumata) and its fitness consequences. J Anim Ecol 66:113-121. doi: $10.2307 / 5969$

Warrington S (1985) Consumption rates and utilization efficiencies of four species of polyphagous Lepidoptera feeding on sycamore leaves. Oecologia 67:460-463. doi:10.1007/BF00790015

Winstad OPL, Hagen SB, Jepsen SB, Kapari L, Schott T, Ims RA (2011) Phenological diversity in the interactions between winter moth (Operophtera brumata) larvae and parasitoid wasps in sub-arctic mountain birch forest. Bull Entomol Res 101:705-714. doi: $10.1017 /$ S0007485311000277

Wint W (1983) The role of alternative hostplant species in the life of a polyphagous moth, Operophtera brumata (Lepidoptera: Geometridae). J Anim Ecol 52:439-450. doi:10.2307/4564 